\title{
Evaluation of the Effects of Corticosteroids on Histamine Release by ex Vivo Cutaneous Microdialysis
}

\author{
Carol Courderot-Masuyer ${ }^{1}$, Sophie Robin ${ }^{1}$, Hélène Tauzin ${ }^{1}$, Sylvain Harbon ${ }^{2}$, Sophie Mac-Mary ${ }^{3}$, \\ Alexandre Guichard ${ }^{4}$, Patrice Muret ${ }^{5}$, Philippe Humbert ${ }^{6 *}$ \\ ${ }^{1}$ Bioexigence SARL, Espace Lafayette, 8 rue Alfred de Vigny, Besançon, France; ${ }^{2}$ Plastic Surgery, 9 rue Klein, Saint Vincent Clinic, \\ Besançon, France; ${ }^{3}$ Skinexigence SAS, immeuble Bioparc, 2 rue du Dr Paul Milleret, Besançon, France; ${ }^{4}$ Research and Clinicl Cen- \\ ter on the Tegument (CERT); Clinical Investigation Center (CIC BT506), Department of Dermatology, Besançon University Hospi- \\ tal, Besançon, France; ${ }^{5}$ Laboratory of Clinical and Toxicology Pharmacology, Jean Minjoz University Hospital, Besancon, France; \\ ${ }^{6}$ University of Franche-Comté, Inserm U1098, SFR FED 4234 IBCT, Besançon, France. \\ Email: "philippe.humbert@univ-fcomte.fr
}

Received August $2^{\text {nd }}, 2013$; revised August 27 $7^{\text {th }}, 2013$; accepted September $2^{\text {nd }}, 2013$

Copyright (c) 2013 Carol Courderot-Masuyer et al. This is an open access article distributed under the Creative Commons Attribution License, which permits unrestricted use, distribution, and reproduction in any medium, provided the original work is properly cited.

\begin{abstract}
The purpose of the study was to evaluate the effects of corticosteroids on histamine release and to compare their potency with the MacKenzie classification based on their vasoconstrictor effects. Thanks to ex vivo cutaneous microdialysis, we studied histamine-induced release over a period of time on excised abdominal skin from women. Eight corticosteroids were topically applied with occlusive dressing onto the skin, above probes, before anti-IgE injection. Histamine levels were assessed by an EIA method. In order to compare the different corticosteroids, AUC was calculated allowing an estimation of the amount of released histamine for $60 \mathrm{~min}$ of ex vivo cutaneous microdialysis. Diflucortolone $0.1 \%$ and micronized betamethasone dipropionate $0.05 \%$ are considered as corticosteroids with high potency in MacKenzie classification. Betamethasone dipropionate associated with propylene glycol $0.05 \%$, belongs to a stronger class in Mackenzie classification. Our results showed that the decrease in histamine release was more important with difluocortolone than with both of these corticosteroids. Therefore there was no correlation between the vasoconstrictor potency of topical corticosteroids and their ability to inhibit histamine release.
\end{abstract}

Keywords: MacKenzie Test; Corticosteroids; ex Vivo Cutaneous Microdialysis; Histamine

\section{Introduction}

The McKenzie's classification of topical corticosteroids is based on the ability to produce the blanching of the skin when they are in contact with them [1,2]. The intensity of skin blanching has been correlated with drug potency and the degree of drug delivery through the stratum corneum. The vasoconstrictor assay has also been used to measure the bioavibility and bioequivalence of topical corticosteroids formulations and was adopted in 1995 for bioequivalence determination by the US Food and Drug Administration (FDA) [3,4]. The technique consisted of the application of corticosteroid solutions on the skin covered with plastic occlusive bandages. The results were evaluated 16 hours after application. This technique described a quantitative comparison of the vasoconstrictor effect of topically applied corticosteroids in healthy

"Corresponding author. human skin. However, there is no direct proof that the vasoconstrictor and anti-inflammatory activities are correlated. Amongst potentially suitable surrogates for in vivo clinical tests, there are in vitro dermatopharmacokinetic methods such as the Franz cells system $[5,6]$ and ex vivo cutaneous microdialysis, in which the rate and extent of permeation through ex vivo skin is measured. In Franz cells, the subcutaneous fat was removed, not in $e x$ vivo cutaneous microdialysis allowing a model closer to the in vivo conditions. Even though the blood flow is not present, we can compare the cutaneous permeation of different formulations of corticosteroids. The microdialysis (MD) principle can be compared to an artificial blood vessel. MD sampling is performed by placing a tubular MD membrane into the dermis, parallel to the skin's surface. The probe, which is permeable to water and small molecules, is continuously perfused with a physiological buffer solution at a low flow rate. Unbound substances 
present in the skin can cross the membrane and enter the lumen probe in proportion to a concentration gradient [7]. Leveque et al. compared Franz cells and microdialysis for the skin absorption of salicylic acid and showed that the permeation profiles of salicylic acid determined by the both methods were similar [8]. MD can follow the evolution of dermis concentrations of endogenous components as well as exogenous components over a period of time. Topical corticosteroids are commonly used in the treatment of immuno-allergic conditions. We decided to carry out an experiment in order to measure directly the ability of topical corticosteroids to inhibit histamine release in an original ex-vitro model using cutaneous microdialysis because the integrity of skin barrier function is maintained. We compared the McKenzie classification of corticosteroids to this new classification according their effect on histamine release. Indeed mast cells are well known to play a central role in the formation of allergic inflammation and contribute to the pathogenesis of allergic diseases, including atopic dermatitis and psoriasis. So histamine plays a pivotal role in the pathogenesis of allergic inflammation. It is known that the dermis of psoriatic plaques contains an increased number of mast cells [9]. Krogstad et al. reported that histamine concentration and release are increased in lesional skin of psoriatic patients [10]. Indeed mast cells reside in all vascularized tissues and particularly high mast cell numbers can be found at the interfaces of host and environment, such as the skin. Release of histamine and "slow reacting substance of anaphylaxis" from mast cells following crosslinking of cell-bound IgE by allergen was demonstrated in 1985 by Ishizaka et al. [11]. Our study is based on experiments performed by Petersen et al. who induced histamine release from resident dermal mast cells of excised female abdominal skin with an intradermal injection of a solution of anti-IgE with a maximum peak around 15 minutes of microdialysis [12]. Thus it is possible to calculate the area under the curve for the release of histamine and to use this data to classify the corticosteroids in accordance with their effects on histamine release.

\section{Materials and Methods}

\section{Products}

Eight corticosteroids creams were obtained from pharmacy:

- micronized betamethasone dipropionate 0.05\% (Diprosone $\left.^{\circledR}\right)(0.05 \% \mathrm{mBD})$

- betamethasone dipropionate $0.05 \%$ with propylene glycol (Diprolene ${ }^{\circledR}$ ) (BdD + PG 0.05\%)

- desonide $0.05 \%$ (Tridesonit $^{\circledR}$ ) (DES 0.05\%)

- desonide 0.1\% (Locapred ${ }^{\circledR}$ ) (DES 0.1\%)

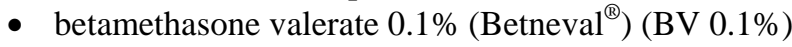

- $\quad$ diflucortolone valerate $0.1 \%$ (Nerisone ${ }^{\circledR}$ ) (DF 0.1\%)

- hydrocortisone butyrate $0.1 \%$ (Locoid $^{\circledR}$ ) (HB 0.1\%)

- clobetasol propionate 0.05\% (Dermoval ${ }^{\circledR}$ ). (CP 0.05\%) Anti-IgE solution was purchased from Dako (France). Histamine EIA kits were obtained from Beckman Coulter (Paris, France).

\section{Skin specimens}

For these experiments, 16 excised abdominal skin (operative wastes) were obtained from surgery procedure and were used as soon as possible after their excision (mean age of women: $41.0 \pm 2.3$ years). The allergic status of the donors was not known. Informed consent was obtained from each subject before surgery. Skin fragments were cut and placed immediately in phosphate buffer (PBS, PAA laboratories, France) and the temperature of $37^{\circ} \mathrm{C}$ of phosphate buffer was maintained during the experiments. The cutting of skin fragments makes it possible to repeat the measurements of histamine release twelve times for each corticosteroid after the application of the cream.

\section{Microdialysis Experiment}

The microdialysis system consisted of a CMA $/ 100^{\circledR}$ syringe pump (Phymed, Paris, France) and CMA/140 microfraction collector, which collected samples. The microdialysis probes $\left(\mathrm{CMA} / 20^{\circledR}\right)$ had a $20-\mathrm{kD}$ cutoff with a polycarbonate membrane (length $10 \mathrm{~mm}$. For each corticosteroid, a total of 12 microdialysis probes were used to determine their potency on the inhibition of histamine release after anti-IgE antibody injection. So each skin fragment was cut into several parts. Histamine release was induced after 1 hour of stabilization following the cutting of the skin and the insertion of microdialysis probes.

Microdialysis samples were collected 5 minutes before the induction of histamine liberation (T0) and the microdialysis lasted 1 hour with sampling of extracellular dermal fluid every 5 minutes. Probes were used in order to determine basal histamine release after anti-IgE injecttion.

The corticosteroids tested were topically applied with occlusive dressing (Tegaderm ${ }^{\mathrm{TM}}$, 3M, France) on the skin above each probe, four hours before anti-IgE injection. Microdialysis started 5 minutes before the histamine released and lasted 1 hour with sampling every 5 minutes (Figure 1).

\section{Determination of histamine in dialysates}

The concentration of histamine in the dialysate was determined by EIA using a commercially available analytic kit for histamine. In order to compare the different corticosteroids, AUC (area under the curve) was calculated allowing an estimation of the amount of released histamine during the period of $60 \mathrm{~min}$ of microdialysis on excised skins. For each skin fragment, the kinetic 


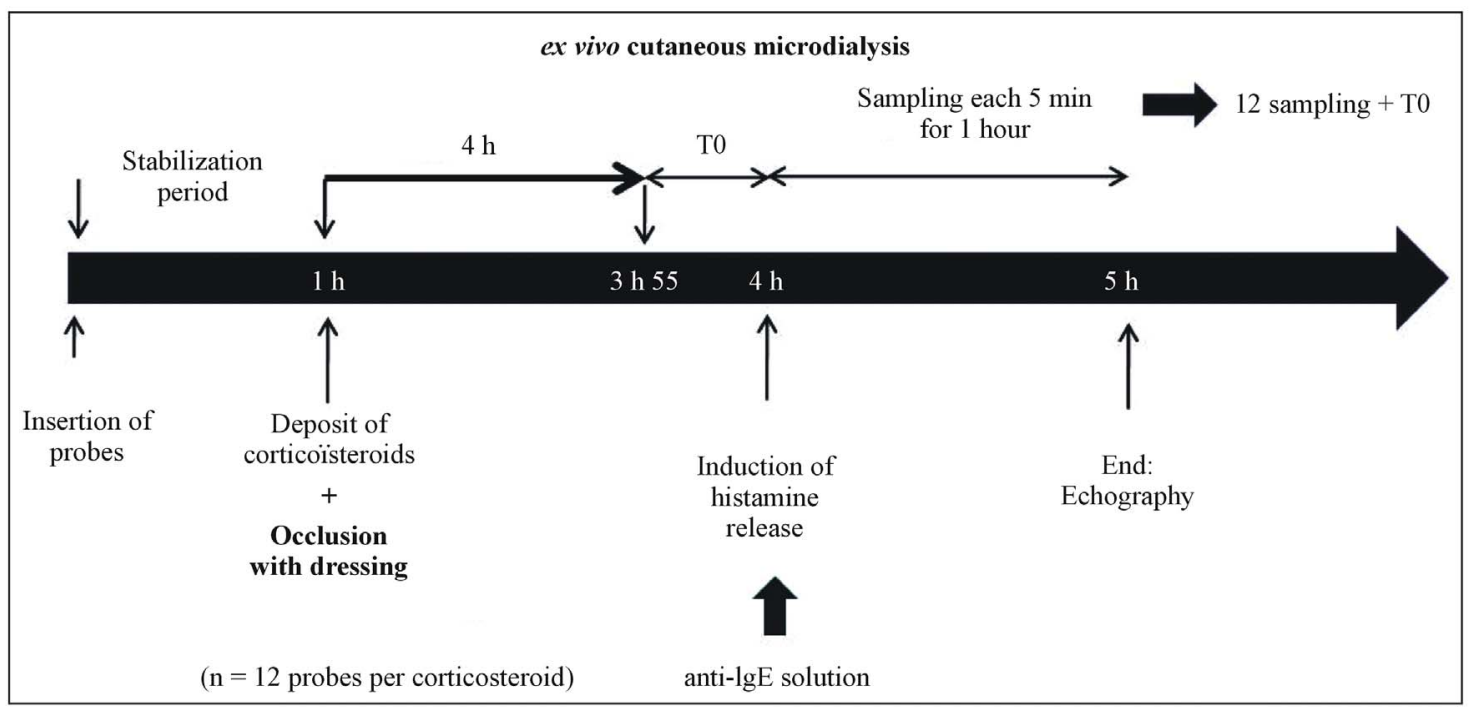

Figure 1. Schematic representation of experimental protocol of histamine-induced model.

curve of histamine release without the presence of corticosteroids (control) was plotted. After 20 minutes, the release of histamine reached a maximum and was considered as $100 \%$. The percentage of histamine was calculated for each time in each curve with and without corticosteroids.

For each curve, area under the curve was calculated using GraphPAD Prism software. The results were expressed as the percentage in comparison to AUC of control curve

\section{Statistics}

Results are expressed as means \pm SEM. Statistical analyses were performed by using one way or two ways variance analysis followed if necessary by Fischer test. Values were considered significantly different when $\mathrm{p}<$ 0.05 .

\section{Results}

Twelve skin fragments were used in order to test each corticosteroid cream on the histamine release. The histamine release induced by anti-IgE antibody was recorded after a stabilization period following the cutting of excised female abdominal skin and the insertion of the probe. This stabilization period makes it possible to determine the basal quantity of histamine present in skin fragments. Histamine concentrations increased and a plateau was obtained 20 minutes after anti-IgE induction. Thus it is possible to calculate the area under the curve for the release of histamine. The second part of the experiment consisted of applying the different corticosteroids creams 4 hours before the induction of histamine release. The results demonstrated that the plateau was lower than the control after the induction of histamine release in the presence of corticosteroids such as clobetasol propionate (CP 0.05\%) (Figure 2). During the 60 minutes of the experiment, histamine dermal levels decreased in the presence of each corticosteroid and made it possible to calculate Area Under the Curve (AUC) for each corticosteroid. The area under the plot of dermal concentration of histamine against time after corticosteroid administration is used in the estimation of the bioavailability of histamine in the dermis showing the effects of corticosteroids in the treatment of immuno-allergic diseases. The classification of corticosteroids according to the value of AUC showed that micronized betamethasone dipropionate (mBdP $0.05 \%$ ), betamethasone dipropionate with propylene glycol (BdP + PG 0.05\%) or desonide, (DES 0.05\%) were less powerful than in McKenzie classification (Figure 3 and Table 1). Difluocortolone (DF $0.1 \%$ ) showed to have the more potent effect after clobetasol propionate (CP $0.5 \%$ ) on histamine release.

\section{Discussion}

An allergy is an overreaction of the immune system following contact with a substance usually foreign to the body. Mast cells play a key role in the immediate phase of allergic reactions and also in the inflammatory process. When activated by direct contact, by cross-linking of IgE receptors, or by activated complement proteins, a mast cell rapidly releases numerous chemical mediators such as serotonin, histamine, tryptase or heparin by a mechanism of exocytosis. Mast cells express a high-affinity receptor for the Fc region of IgE. This receptor is of such high affinity that binding of IgE molecules is essentially irreversible. As a result, mast cells are coated with IgE. IgE molecules are produced by plasma cells and are specific to one particular antigen. Petersen et al. deve- 


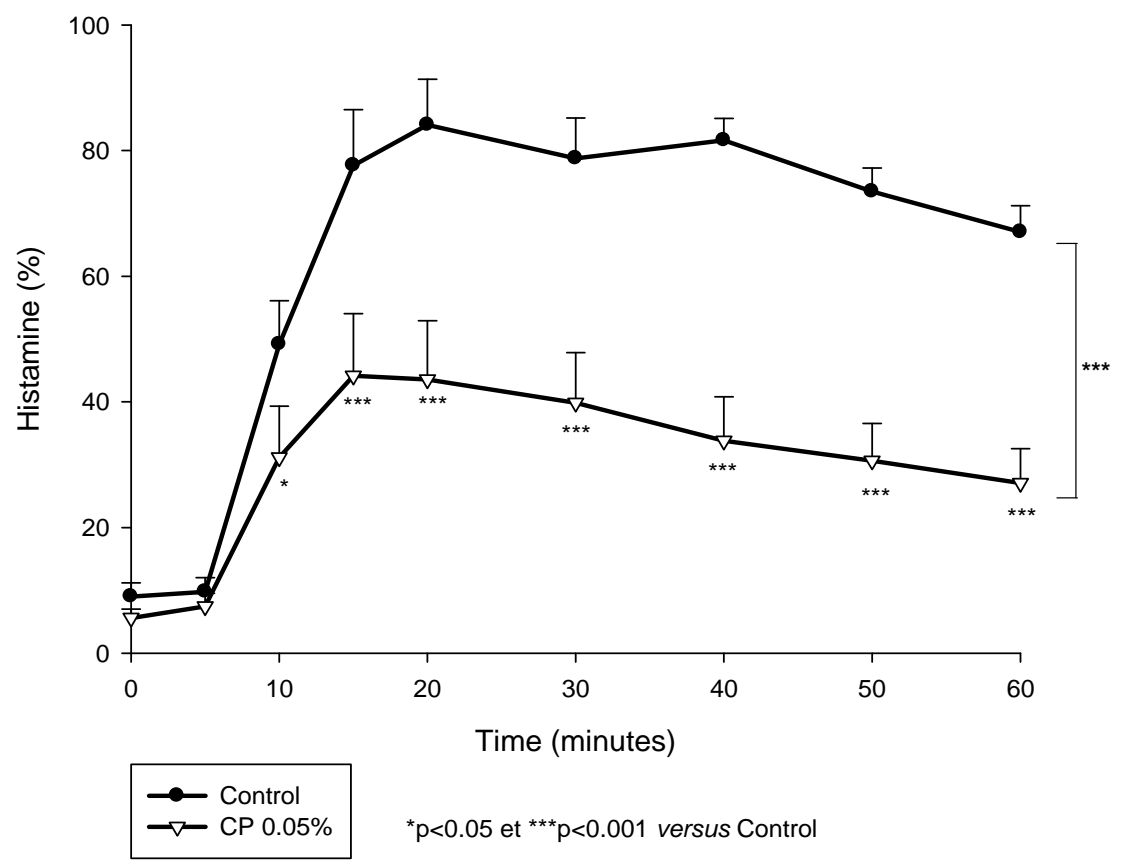

Figure 2. Skin release of histamine after anti-IgE injection in the presence or not of PC $0.05 \%$ ). Propionate clobetasol $0.05 \%$ (Sampling intervals were $5 \mathrm{~min}$. Histamine concentrations in dialysates are shown over 60 min. ${ }^{*}$ p $<0.05$ and ${ }^{* * *}$ p $<0.001$ versus control.

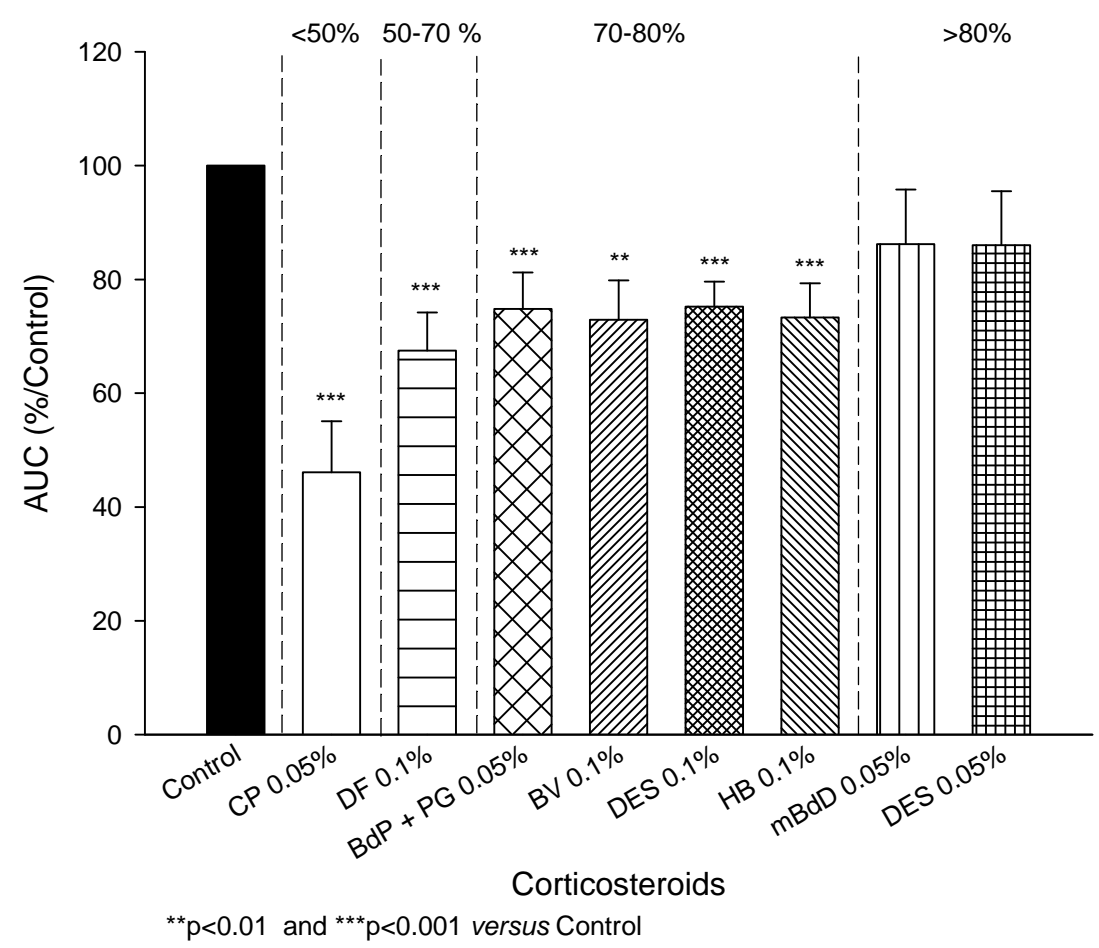

Figure 3. Classification of corticosteroids using the estimation of the amount of released histamine (AUC) during the period of 60 min of microdialysis on excised skins in the presence of corticosteroids. ${ }^{* *} p<0.01$ and ${ }^{* * *} p<0.001$ versus control.

loped a microdialysis technique allowing the measurement of histamine release from intact human skin mast cells ex vivo [12] using intradermal injection of anti-IgE. The kinetics of histamine release in the skin ex vivo by
anti-IgE showed a maximum peak around 15 minutes of microdialysis comparable to that obtained in the present study. So this microdialysis technique made it possible to test the potency of several topical corticosteroids on ex 
Table 1. Potency of topical corticosteroids. Comparison between MacKenzie classification and the new classification using histamine-induced model

\begin{tabular}{|c|c|c|c|c|}
\hline $\begin{array}{l}\text { Potency Mackenzie } \\
\text { classification }\end{array}$ & Topical corticosteroid & Formulation & French trade name & $\begin{array}{l}\text { Potency Inhibition of } \\
\text { histamine release }\end{array}$ \\
\hline Ultra high & Clobetasol propionate (CP 0.05\%) & Cream, $0.05 \%$ & Dermoval $^{\circledR}$ & Ultra high \\
\hline High & Micronized betamethasone dipropionate (mBdD 0.05\%) & Cream, 0.05\% & Diprosone $^{\circledR}$ & Low \\
\hline Ultra High & $\begin{array}{c}\text { Betamethasone dipropionate } \\
\text { with propylene glycol (BdD + PG 0.05\%) }\end{array}$ & Cream, 0.05\% & Diprolene $^{\circledR}$ & Moderate \\
\hline High & Betamethasone valerate (BV 0.1\%) & Cream, $0.1 \%$ & Betneval $^{\circledR}$ & Moderate \\
\hline High & Diflucortolone (DF 0.1\%) & Cream, $0.1 \%$ & Nerisone $^{\circledR}$ & High \\
\hline Moderate & Desonide (DES 0.1\%) & Cream, $0.1 \%$ & Locapred $^{\circledR}$ & Moderate \\
\hline Moderate & Desonide (DES 0.05\%) & Cream, 0.05\% & Tridesonit $^{\circledR}$ & Low \\
\hline Moderate & Hydrocortisone butyrate (HB $0.1 \%$ ) & Cream, $0.1 \%$ & Locoid $^{\circledR}$ & Moderate \\
\hline
\end{tabular}

vivo model of histamine release. Indeed topical corticosteroid application to the skin is a standard therapy in immuno-allergic diseases. Up till the present moment, it was thought that the effectiveness of topical corticosteroids results especially in a vasoconstriction of superficial dermis and a decrease in capillary permeability, which results in the rapid reduction of edema and erythema. The degree of vasoconstriction seems to be related to the potency and the absorption of the topically applied steroid and has been used in the Mckenzie vasoconstrictor assay [1].

This assay, introduced by McKenzie and Stoughton [1], involves the evaluation of the degree of skin blanching over a period following the application of topical corticosteroid products to the skin of healthy human subjects. It can be carried out by visual assessment of the degree of blanching at the application site or by an instrumental method of assessment using a chromameter. The intensity of the skin blanching response is related to the amount of corticosteroid that has penetrated into the skin [13]. Various publications have shown that the precision, sensitivity and repeatability of this assay are adequate for the assessment of the bioequivalence of topical corticosteroid formulations [14-19]. The degree of hydration of the horny layer of epidermis affects its permeability for corticosteroids and their transport through the skin. Occlusion increases the permeability of the skin for corticosteroids, resulting in an increased degree of skin hydration [20]. There is also a relationship between the vehicule composition of corticosteroids and the skin blanching. Indeed the release of corticosteroids from creams depends on the composition of the vehicule and can contribute to the blanching. Propylene glycol associated with betamethasone dipropionate (Diprolene ${ }^{\circledR}$ ) increases the solubilization of its molecule and improves the blanching compared to the formulation without propylene glycol (Diprosone ${ }^{\circledR}$ ). So the skin blanching was used as a measure of the percutaneous absorption of corticosteroids from topical formulations. Up to now, human skin blanching is used to evaluate the efficacy of topical corticoids prior to their final testing during clinical trials.

However there is no direct proof that the vasoconstrictor and anti-inflammatory activities are correlated. Since topical corticosteroids are commonly used in the treatment of immuno-allergic conditions, we firstly carried out in the present study, an experiment in order to measure directly the ability of topical corticosteroids to inhibit histamine release in an original ex-vitro model which allowed studies of the bioequivalence of topical corticoids formulations without the presence of blood flow. Secondly we compared the McKenzie classification of corticosteroids to this new classification according their effect on histamine release from resident dermal mast cells. This original model consists in an ex vivo skin treated by injection of anti-IgE antibody because mast cells also reside in the skin. The results showed that topical corticosteroids inhibited directly the release of histamine in addition to vasoconstriction properties. A pretreatment of the skin by corticosteroids for 4 hours with occlusive dressing made it possible to decrease the dermal histamine levels. So McKenzie classification of corticosteroids is not correlated to their potency of inhibition on histamine release. Micronized betamethasone dipropionate (mBdP 0.05\%), betamethasone dipropionate with propylene glycol (BdP + PG 0.05\%) or desonide, (DES $0.05 \%$ ) were less powerful than in McKenzie classification. Our model also showed that the presence of propylene glycol induced an increase in the activity of betamethasone on histamine release. It is noteworthy that difluocortolone (DF 0.1\%) showed to have a more potent effect after clobetasol propionate (CP 0.5\%) on histamine release.

\section{Conclusion}

In conclusion, we did not find the same results concern- 
ing the potency of corticosteroids according to MacKenzie classification and the inhibition of histamine release. These results show us that a new classification of the potency of corticosteroids should be established to treat correctly the patients according to the origin of the observed disturbances. These results invite us to consider the power of topical corticosteroids differently depending on their target action (anti-allergic, anti-inflammatory...). New ex vivo models should be developed in order to observe the direct effects of corticosteroids on the release of inflammatory mediators. The method, which we have developed, should lead to the study of clinical disease models for immuno-allergic clinical validation.

\section{REFERENCES}

[1] A. W. MacKenzie and R. B. Stoughton, "A Method for Comparing Percutaneous Absorption of Steroids," Archives of Dermatology, Vol. 86, No. 11, 1962, pp. 608-610. doi:10.1001/archderm.1962.01590110044005

[2] A. W. McKenzie, "Percutaneous Absorption of Steroids," Archives of Dermatology, Vol. 86, No. 11, 1962, pp. 611614. doi:10.1001/archderm.1962.01590110047006

[3] S. Wiedersberg, C. S. Leopold and R. H. Guy, "Bioavailability and Bioequivalence of Topical Glucocorticoids,” European Journal of Pharmaceutics and Biopharmaceutics, Vol. 68, No. 3, 2008, pp. 453-466. doi:10.1016/j.ejpb.2007.08.007

[4] Y. Narkar, "Bioequivalence for Topical Products-An Update,” Pharmaceutical Research, Vol. 27, No. 12, 2010, pp. 2590-2601. doi:10.1007/s11095-010-0250-3

[5] Organisation for Economic Co-operation and Development (OECD), "Test Guideline 427: In Vitro Method," Paris, 2004.

[6] T. J. Franz, P. A. Lehman and S. G. Raney, "Use of Excised Human Skin to Assess the Bioequivalence of Topical Products," Skin Pharmacology and Physiology, Vol. 22, No. 5, 2009, pp. 276-286. doi:10.1159/000235828

[7] A. Le Quellec, S. Dupin, P. Genissel, S. Saivin, B. Marchand and J. P. M. Houin, "Microdialysis Probes Calibration: Gradient and Tissue Dependent Changes in No Flux and Reverse Dialysis Methods," Journal of Pharmacoogical and Toxicological Methods, Vol. 33, No. 1, 1995, pp. 11-16. doi:10.1016/1056-8719(94)00049-A

[8] N. Leveque, S. Makki, J. Hadgraft and P. Humbert, "Comparison of Franz Cells and Microdialysis for Assessing Salicylic Penetration through Human Skin,” International Journal of Pharmaceutics, Vol. 269, No. 2, 2004, pp. 323-328. doi:10.1016/j.ijpharm.2003.09.012

[9] I. Brody, "Mast Cell Degranulation in the Evolution of Acute Eruptive Guttate Psoriasis Vulgaris,” Journal of Investigative Dermatology, Vol. 82, No. 5, 1984, pp. 460464. doi:10.1111/1523-1747.ep12260955

[10] A. L. Krogstad, G. Lonnroth, B. F. G. Larson and B. G.
Wallin, "Nerve-Induced Histamine Release Is of Little Importance in Psoriatic Skin,” British Journal of Dermatology, Vol. 139, No. 5, 1998, pp. 403-409. doi:10.1046/j.1365-2133.1998.02402.x

[11] T. Ishizaka, D. H. Conrad, T. F. Huff, D. D. Metcalfe, R. L. Stevens and R. A. Lewis, "Unique Features of Human Basophilic Granulocytes Developed in in Vitro Culture,” International Archives of Allergy and Applied Immunology, Vol. 77, No. 1-2, 1985, pp. 137-143. doi:10.1159/000233768

[12] L. J. Petersen, K. Brasso, M. Pryds and P. S. Skov, "Histamine Release in Intact Human Skin by Monocyte Chemoattractant Factor-1, RANTES, Macrophage Inflammatory Protein-1 Alpha, Stem Cell Factor, Anti-IgE, and Codeine as Determined by an ex Vivo Skin Microdialysis Technique,” Journal of Allergy and Clinical Immunology, Vol. 98, No. 4, 1996, pp. 790-796. doi:10.1016/S0091-6749(96)70128-8

[13] L. K. Pershing, B. S. Silver, G. G. Krueger, V. P. Shah and J. P. Skelly, "Feasibility of Measuring the Bioavailability of Topical Betamethasone Dipropionate in Commercial Formulations Using Drug Content in Skin and a Blanching Bioassay,” Pharmaceutical Research, Vol. 9, No. 1, 1992, pp. 45-51. doi:10.1023/A:1018975626210

[14] B. W. Barry and R. Woodford, "Activity and Bioavailability of Topical Corticosteroids: In Vivo/In Vitro Correlations for the Vasoconstrictor Test," Journal of Clinical Pharmacology, Vol. 3, No. 1, 1978, pp. 43-65.

[15] K. H. Burdick, "Corticosteroid Bioavailability Assays: Correlation with a Clinical Study," Acta Dermato-Venereologica: Supplement (Stockholm), Vol. 52, No. 67, 1971, pp. 19-23.

[16] B. W. Barry, "Bioavailability of Topical Steroids," Dermatologica, Vol. 152, Suppl. 1, 1976, pp. 47-65. doi:10.1159/000257866

[17] G. L. Coleman, I. Kanfer and J. M. Haigh, “Comparative Blanching Activities of Proprietary Diflucortolone Valerate Topical Preparations,” Dermatologica, Vol. 156, No. 4, 1978, pp. 224-230. doi:10.1159/000250920

[18] E. Meyer, A. D. Magnus, J. M. Haigh and I. Kanfer, "Comparison of the Blanching Activities of Dermovate, Betnovate and Eumovate Creams and Ointments," International Journal of Pharmaceutics, Vol. 41, No. 1, 1988, pp. 63-66. doi:10.1016/0378-5173(88)90136-6

[19] E. W. Smith, E. Meyer, J. M. Haigh and H. I. Maibach, "The Human Skin Blanching Assay as an Indicator of Topical Corticosteroid Bioavailability and Potency: An Update,” In: R. L. Bronaugh and H. I. Maibach, Eds., Percutaneous Absorption: Mechanisms, Methodology and Drug Delivery, 2nd Edition, Marcel Dekker, Inc., New York, 1989, pp. 443-460.

[20] J. M. Haigh and L. Kanfer, “Assessment of Topical Corticosteroid Preparations: The Human Skin Blanching Assay," International Journal of Pharmaceutics, Vol. 19, No. 3, 1984, pp. 245-262. doi:10.1016/0378-5173(84)90055-3 